tein mixtures as well as in work with sera of the haptoglobin 1-1 type, and particularly in newborn infants, who usually lack haptoglobin.

I am greatly indebted to Dr. O. Smithies for his interest and advice during the experiments, and to Mrs. E. Poulik for able technical assistance. This work was supported by a grant awarded by the Department of National Health and Welfare.

Department of Public Health,

$$
\text { M. D. Poulik* }
$$

University of Toronto, Toronto.

* Present address: The Child Research Center of Michigan, 660 Frederick Street, Detroit 2, Michigan, U.S.A.).

${ }^{1}$ Smithies, O, Biochem. J., 61, 629 (1955).

Smithies, O., and Poulik, M. D., Nature, 177, 1033 (1956).

${ }^{8}$ Poulik, M. D., Nature, 177, 982 (1956).

- Dixon, O. U., and Smithies, O., Biochim. Biophys. Acta, 28, 198 (1957).

s Poulik, M. D., Can. J. Med. Sci., 30, 417 (1952)

- Smithies, O., and Walker, M. F., Nature, 178, 694 (1956).

\section{Chlorogenic Acid Metabolism in Cider Fermentation}

Chlorogenic ACID is invariably found in ciderapple juices ${ }^{1}$, and our unpublished results show that in some varieties it may constitute more than 0.25 per cent $(w / v)$ of the juice. Paper chromatographic examination of a number of ciders showed that chlorogenic acid frequently disappeared during fermentation. Where caffeic acid was present in the original juice, this acid also disappeared, and these changes occurred only in ciders which showed reduction of quinic acid to dihydroshikimic acid. It seemed likely that chlorogenic and caffeic acids were metabolized by the Lactobacillus found capable of reducing quinic acid to dihydroshikimic acid, namely, L. pastorianus var. quinicus ${ }^{2,3}$.

Work with partially disintegrated cells of this strain indicated that the first stage in the metabolism of chlorogenic acid was hydrolysis to caffeic and quinic acids. Both products were further metabolized, and the metabolism of caffeic acid was investigated by the use of growing cells. A pure culture of the same organism was inoculated into a basal medium ${ }^{2}$ with the addition of 0.025 per cent caffeic acid. After 7 days incubation at $25^{\circ} \mathrm{C}$. under conditions of reduced oxygen tension, the caffeic acid was completely metabolized. In a control flask, to which killed organisms were added, the caffeic acid remained. unchanged. Quantitative oxidation with potassium permanganate of the uninoculated and inoculated media after incubation suggested saturation of the caffeic acid side-chain ${ }^{4}$. Paper chromatographic examination showed that two main products $A$ and $B$ were present ; they were extracted with ether after acidification of the medium and were separated on $a$ silica gel column. $A$ and $B$ reacted on paper chromatograms with the following spray reagents: (1) 1 per cent ferric chloride-l per cent potassium ferricyanide (blue colour); (2) 1 per cent ferric chloride (green colour) followed by exposure to ammonia vapour (purple colour); (3) ammoniacal silver nitrate (black in the cold); (4) diazotized $p$-nitraniline (orange). $A$ gave a violet colour with 1 per cent sodium borate followed by 0.4 per cent ethanolic 2:6 dichloroquinonechlorimide while $B$ gave a maroon colour; $A$ was acidic to bromocresol green while $B$ at the same ooncentration was not detectable with this indicator.
Reactions (2) and (3) suggested that both $A$ and $B$ were compounds of the catechol type. $A$ had the same $R_{F}$ values as dihydrocaffeic acid in 2 per cent acetic acid ${ }^{5}$ and in benzyl alcohol-iso-propyl alcohol - tert.-butyl alcohol - water - formic acid (3: $1: 1: 1: 2$ per cent $)^{6}$, and these two substances showed identical reactions with the spray reagents mentioned above. $A$ after re-crystallization from hot water and from ether-benzene had a melting point of $139^{\circ}$ identical with that of dihydrocaffeic acid. Elementary analysis of $A$ gave $\mathrm{C}, 59.51$ per cent; $\mathrm{H}, 5.63$ per cent; $\mathrm{C}_{9} \mathrm{H}_{10} \mathrm{O}_{4}$ requires $\mathrm{C}, 59.33$ per cent; $\mathrm{H}, 5 \cdot 50$ per cent.

$B$ had a $R_{F}$ value in the benzyl alcohol solvent of 0.93 while that of $A$ was 0.82 . This was in keөping with loss of the carboxyl group from $A$ to give $B$. $B$ was isolated and crystallized from petroleum ether as thin needles with m.p. $38-39^{\circ}$, which rapidly turned brown in air. Ethyl catechol has m.p. $39^{\circ} 7,8$ and rapidly turns brown in air. $B$ and a synthetic specimen of ethyl catechol had identical $R_{F}$ values in the two solvents mentioned above and a mixed melting-point showed no depression. $A$ and $B$ were therefore identified as dihydrocaffeic acid and ethyl catechol respectively.

It is possible that $p$-coumaryl quinic acid, also present in cider-apples ${ }^{9}$, may be motabolized in a similar manner to chlorogenic acid for addition of $p$-coumaric acid to the same basal medium, and inoculation with the same strain of lactobacillus showed that this acid was metabolized.

\section{G. C. WhITING}

J. G. CARR

Department of Agriculture and Horticulture,

University of Bristol,

Long Ashton Research Station, Bristol.

Phillips, J. D., Pollard, A., and Whiting, G. C., J. Sci. Food Agric., 7, 31 (1956)

${ }^{2}$ Carr, J. G., Phillips, J. D., Pollard, A., Whiting, G. C., and Williams, A. H., Chem. and Indust., 1515 (1954).

${ }^{3}$ Carr, J. G., Pollard, A., Whiting, G. C., and Williams, A. H., Biochem . J., 66, 283 (1957).

4 Williams, A. H., Ann. Rep. Agric. Hort. Res. Sta. Bristol, 219 (1952). ${ }^{5}$ Williams, A. H., Chem. and Indust., 120 (1955).

- Stark, J. B., Goodban, A. E., and Owens, H. S., Anal. Chem., 23, 413 (1951).

'Johnson, T. B., and Hodge, W. H., J. Amer. Chem. Soc., 35, 1023 (1913).

B Delange, R., C.R. Acad. Sci., Paris, 138, 1702 (1904).

- Cartwright, R. A., Roberts, E. A. H., Flood, A. E., and Williams, A. H., Chem. and Indust., 1062 (1955).

\section{Loss of Immunizing Power of Staphylo- coccal Toxin during Routine Toxoiding with Formalin}

IN order to render staphylococcal toxic supernatants safe for use as active immunizing agents, it is customary to incubate them with formalin, in concentrations of $0.3-0.8$ per cent at temperatures between $37^{\circ}$ and $40^{\circ} \mathrm{C}$. for periods of up to two weeks ${ }^{1,2}$.

In the work to be described, the effect of this process on the antigenicity of a protective factor in staphylococcal toxic supernatants was examined in mice.

The staphylococcal toxic supernatent used had been prepared from cultures of strain $C N 56$, grown for three days on modified Dolman's medium in an atmosphere of oxygen containing 20 per cent carbon dioxide, and was stored at $2^{\circ} \mathrm{C}$. with 0.02 per cent 